\title{
Large-Scale Grid Integration of Renewable Energy Resources with a Double Synchronous Controller
}

\author{
Majid Mehrasa ${ }^{1}$, Edris Pouresmaeil ${ }^{2, *} \mathbb{C}$, Hamid Soltani ${ }^{3}$, Frede Blaabjerg ${ }^{4}(\mathbb{D}$, \\ Maria R. A. Calado ${ }^{5}$ ad and João P. S. Catalão ${ }^{6, * \mathbb{D}}$ \\ C-MAST, University of Beira Interior, 6201-001 Covilhã, Portugal; m.majidmehrasa@gmail.com \\ Department of Electrical Engineering and Automation, Aalto University, 00076 Aalto, Finland \\ Vestas, 8200 Aarhus, Denmark; hasol@vestas.com \\ Aalborg University, 9220 Aalborg, Denmark; fbl@et.aau.dk \\ University of Beira Interior and Instituto de Telecomunicações, 6201-001 Covilhã, Portugal; rc@ubi.pt \\ Faculty of Engineering of the University of Porto and INESC TEC, 4200-465 Porto, Portugal \\ * Correspondence: edris.pouresmaeil@aalto.fi (E.P.); catalao@fe.up.pt (J.P.S.C.)
}

Received: 4 November 2019; Accepted: 10 December 2019; Published: 16 December 2019

check for updates

\begin{abstract}
This paper provides virtual inertia and mechanical power-based double synchronous controller (DSC) for power converters based on the $\mathrm{d}$ - and q-components of the converter current to assure the stable operation of the grid with the penetration of large-scale renewable energy resources (RERs). The DSC is projected based on emulating both the inertia and mechanical power variables of the synchronous generators (SGs), and its performance is compared with a non-synchronous controller (NSC) that is without these emulations. The main contributions of the DSC are providing a large margin of stability for the power grid with a wide area of low and high values of virtual inertia, also improving significantly power grid stability (PGS) with changing properly the embedded virtual variables of inertia, mechanical power, and also mechanical power error. Also, decoupling features of the proposed DSC in which both $\mathrm{d}$ and q components are completely involved with the characteristics of SGs as well as the relationship between the interfaced converter and dynamic models of SGs are other important contributions of the DSC over the existing control methods. Embedding some coefficients for the proposed DSC to show its robustness against the unknown intrinsic property of parameters is another contribution in this paper. Moreover, several transfer functions are achieved and analyzed that confirm a more stable performance of the emulated controller in comparison with the NSC for power-sharing characteristics. Simulation results confirm the superiority of the proposed DSC in comparison with other existing control techniques, e.g., the NSC techniques.
\end{abstract}

Keywords: renewables; non-synchronous controllers; stability of the grid; virtual inertia

\section{Introduction}

Renewable Energy Resources (RERs) have experienced more than $30 \%$ growth area in new electricity networks compared with the growth of fossil fuel-based power production [1,2]. The lack of inertia in the structure of converter-based generators increases the negative impacts on the stable operation of the power grid [3-5]. Many applications related to RERs have been addressed in recent references such as hybrid microgrid [6], stand-alone microgrid [7], smart residential user [8,9], and energy hub [10]. In this route, control of power converters in microgrid structures is an important issue regarding large shares of RERs along with highly controllable power processors based on power electronics [11]. To deal with the unstable behaviors of the grid due to the renewables integration at a large scale, several solutions have frequently been considered in the literature that are the reactive power compensation-based controllers [12,13], the distributed energy storage systems [14-17], 
emulated synchronous generator (SG)-based control strategies $[18,19]$, and the demand response from thermostatically controlled loads [20,21].

Among these solutions, imitating the characteristics of the synchronous generators, i.e., inertia and mechanical power, can provide a wide stability margin for voltage magnitude and frequency of power grid under high penetration of RERs [22]. In order to reach a stable operation for the multi-virtual SG microgrid in transient operating conditions, the voltage angle deviations (VADs) of generators with respect to the angle of the center of inertia are designed [23]. Also, particle swarm optimization is used to set virtual SG parameters for obtaining a smooth transition after a change or disturbance as well as maintaining the VADs of generators within a specific limit.

In [24], two features of SG, i.e., the inertia and the damping power, have been placed in the proposed controller to regulate the frequency amplitude and the power flow from the energy storage system and also the optimization of control parameters have been continuously executed through a self-tuning algorithm. For a voltage source converter used in HVDC, a synchronous generator emulation-based control technique has been proposed in [25] that has been placed in two inner and outer control loops. A comprehensive virtual SG control strategy was proposed in [26] for the full converter wind turbine along with a multilevel storage system that leads to operating under both grid-connected and stand-alone modes. The emulation of the behaviors of the SG for the control of a voltage source converter in both transient and steady-state operating conditions is considered in [27]. In that paper, two hysteresis current controllers, i.e., standard and space vector-based, are introduced for a virtual SG-based current controller in real-time [27]. In [28,29], evaluations based on the frequency domain transfer functions have been presented to verify the operation of SGs-based control techniques.

This paper presents a new control strategy, i.e., the double synchronous controller (DSC) for the integration of large scale RERs into the power grid through the power electronics converters. The performance of the DSC is compared with a non-synchronous controller (NSC), which is not included by any emulation which has not been investigated in other related works of the authors in [30-36]. The main contributions of proposed DSC over existing methods can be stated as (1) more comprehensive relationship between interfaced converter and SGs dynamic models, (2) a more decoupling feature for both $\mathrm{d}$ and q components, (3) those components are completely involved with the SG's characteristics, (4) robustness feature against the unknown intrinsic property of parameters, and (5) more detailed features of the SGs are contributed to provide appropriate virtual inertia. In addition, regarding the mentioned contributions of this manuscript, the robustness features and error curves have not been paid attention in previous works of the authors in [30-36].

The rest of this paper is organized as follows. The problem statement is defined in Section 2, and the DSC and the NSC controllers are proposed in Section 3. In Section 4, the NSC and DSC active and reactive error curves are presented. Section 5 is allocated to analyzing the power-sharing capability issue. The angular frequency error evaluation is accomplished in Section 6. Finally, simulations results are presented in Section 7, and the conclusions are drawn in Section 8.

\section{The Problem Statement}

Figure 1 shows the basic system for a large-scale interconnection of renewable energy resources into the power grid. Three power sources except for the power grid can be seen where each source has its obligations to produce the required active and reactive power.

Based on the connected loads at the PCC, SG, a controlled interfaced converter empowered by RER and just-feeding interfaced converter empowered by RERs, should generate specific power. The problem is that a sudden connection or disconnection of just-feeding interfaced converter RERs may occur and lead to instability for the grid frequency and voltage magnitude because of a lack of sufficient inertia in the control-based interfaced converter. However, the SG may have good response due to its inherent inertia; but the grid might totally become unstable. To deal with this problem, the proposed controller of the interfaced converter should emulate the inherent features of SG to show acceptable and fast damping responses to any unexpected high penetration of just-feeding RERs. 
The just-feeding RERs are assumed to produce only constant active and reactive power with no change. As the limitation of the system shown in Figure 1, both an interfaced converter and grid can maximally generate a nominated power.

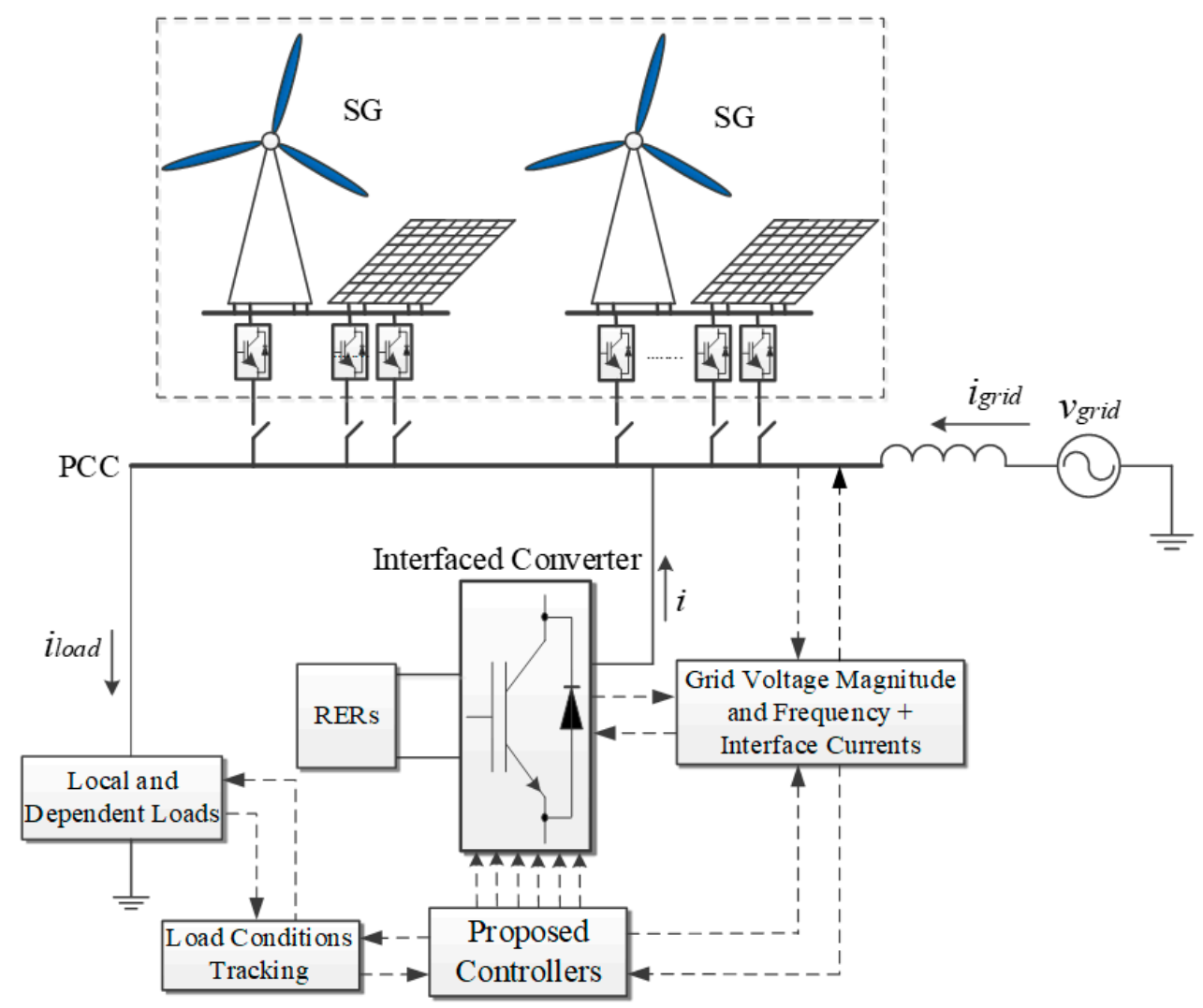

Figure 1. General model for integration of large-scale Renewable Energy Resources (RERs).

\section{The Proposed Control Techniques}

\subsection{The Non-Synchronous Controller (NSC)}

The dynamic model is given by:

$$
\frac{d}{d t}\left[\begin{array}{c}
L i_{d} \\
L i_{q} \\
C v_{d c}
\end{array}\right]=\left[\begin{array}{ccc}
-R & \omega L & u_{d} \\
-\omega L & -R & u_{q} \\
-u_{d} & -u_{q} & 0
\end{array}\right]\left[\begin{array}{c}
i_{d} \\
i_{q} \\
v_{d c}
\end{array}\right]+\left[\begin{array}{c}
-v_{d} \\
-v_{q} \\
-i_{d c}
\end{array}\right]
$$

By assuming $P=i_{d} v_{d}$ and $Q=-i_{q} v_{d},(1)$ can be given as:

$$
\frac{d}{d t}\left[\begin{array}{c}
\frac{L}{R} P \\
\frac{L}{R} Q \\
R C P_{c 1}
\end{array}\right]=\left[\begin{array}{ccc}
-1 & -\frac{\omega L}{R} & u_{d} \\
\frac{\omega L}{R} & -1 & -u_{q} \\
-u_{d} & u_{q} & 0
\end{array}\right]\left[\begin{array}{c}
P \\
Q \\
P_{c 1}
\end{array}\right]+\left[\begin{array}{c}
-P_{p d} \\
P_{p d q} \\
-P_{c 2}
\end{array}\right]
$$

By transforming (2) into the frequency domain, (3) can be achieved as:

$$
\left[\begin{array}{ccc}
\left(\frac{L}{R} s+1\right) & \frac{\omega L}{R} & -u_{d} \\
-\frac{\omega L}{R} & \left(\frac{L}{R} s+1\right) & u_{q} \\
u_{d} & -u_{q} & R C s
\end{array}\right]\left[\begin{array}{c}
P \\
Q \\
P_{c 1}
\end{array}\right]+\left[\begin{array}{c}
P_{p d} \\
-P_{p d q} \\
P_{c 2}
\end{array}\right]=0
$$


Considering two PI controllers for (3) to compensateboth active and reactive power errors, the proposed NSC can be as displayed in Figure 2. The proposed NSC is only dependent on the power and other specifications of the interfaced converter along with its related compensators.

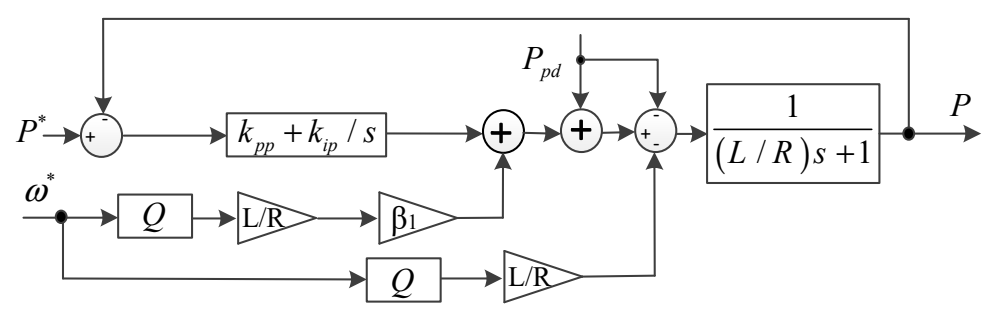

(a)

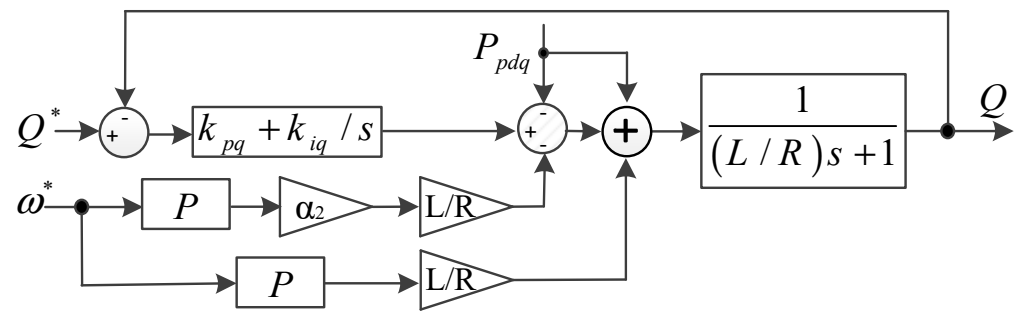

(b)

Figure 2. The projected Non-Synchronous Controller (NSC): (a) d-component and (b) q-component.

3.2. The Double-Synchronous Controller (DSC)

The features of SG can be stated based on:

$$
J \frac{d \omega}{d t}=\frac{P_{m}-P}{\omega}
$$

The error of the angular frequency is given by:

$$
\Delta \omega=\frac{1}{\omega^{*} J} \cdot \frac{\Delta P_{m}-\Delta P}{s+\left(P_{m}^{*}-P^{*}\right) / \omega^{* 2} J}
$$

Equation (5) demonstrates the dynamics of the phase-locked loop in the proposed DSC. The active power error is:

$$
\frac{\Delta P}{s}=\frac{\Delta P_{m}}{s}-\left(\omega^{*} J+\frac{\left(P_{m}^{*}-P^{*}\right)}{\omega^{*} s}\right) \Delta \omega
$$

The reactive power error is:

$$
\frac{\Delta Q}{s}=-\frac{P^{*}}{Q^{*}} \frac{\Delta P_{m}}{s}+\frac{P^{*}}{Q^{*}}\left(\omega^{*} J+\frac{\left(P_{m}^{*}-P^{*}\right)}{\omega^{*} s}\right) \Delta \omega
$$

The dynamic model of the interfaced converter is given as:

$$
\begin{aligned}
\frac{1}{s}\left[\begin{array}{c}
\Delta \omega \\
\Delta P \\
\Delta Q
\end{array}\right]= & {\left[\begin{array}{ccc}
0 & \frac{-1 / \omega^{*} J s}{s+\left(P_{m}^{*}-P^{*}\right) / \omega^{* 2} J} & 0 \\
-\left(\omega^{*} J+\frac{\left(P_{m}^{*}-P^{*}\right)}{\omega^{*} s}\right) & 0 & 0 \\
\frac{P^{*}}{Q^{*}}\left(\omega^{*} J+\frac{\left(P_{m}^{*}-P^{*}\right)}{\omega^{*} s}\right) & 0 & 0
\end{array}\right] } \\
& \times\left[\begin{array}{c}
\Delta \omega \\
\Delta P \\
\Delta Q
\end{array}\right]+\left[\begin{array}{c}
\frac{1}{\omega^{*} J s} \cdot \frac{1}{s+\left(P_{m}^{*}-P^{*}\right) / \omega^{* 2} J} \\
\frac{1}{s} \\
-\frac{P^{*}}{Q^{*}} \frac{1}{s}
\end{array}\right] \Delta P_{m}
\end{aligned}
$$


By accurately analyzing (8), the proposed DSC can be achieved as depicted in Figure 3. Based on the aforementioned points, the coefficients of low pass filter (LPF) and compensators can be driven as:

$$
\begin{gathered}
k_{p p}=\omega^{*} J, k_{i p}=\frac{P_{m}^{*}-P^{*}}{\omega^{*}}, k_{p q}=\omega^{*} J P^{*} / Q^{*} \\
k_{i q}=\frac{\left(P_{m}^{*}-P^{*}\right) P^{*}}{\omega^{*} Q^{*}}, \omega_{1}=1 / \omega^{*} J, \omega_{2}=\frac{P_{m}^{*}-P^{*}}{\omega^{* 2} J}
\end{gathered}
$$

As it can be understood from (9), all the controller and compensator coefficients are related to other parameters of interfaced converter and SG. As a result, the change of virtual inertia J can be used to tune the controller coefficients in DSC. The coefficients $\alpha_{1}, \alpha_{2}, \beta_{1}$, and $\beta_{2}$ as well as the NSC coefficients can be tuned through the trial-error method. The proposed DSC has all features of SG in both its components of controller, and consequently, it can lead to a controller with adjustable inertia effect and faster dynamic response with more effective virtual mechanical variables. In addition, the coefficients $\alpha_{1}, \alpha_{2}, \beta_{1}$, and $\beta_{2}$ are the control factors of the proposed DSC that can provide two decoupled closed-loop controllers. The current control-based dynamic of the proposed DSC is shown as a low pass filter of $1 /((\mathrm{L} / \mathrm{R}) \mathrm{s}+1)$ used at the end of Figure 3. It should be noticed that two coefficients, $\beta_{1}$ and $\alpha_{2}$, can be used to eliminate the problem relating to the unknown intrinsic property of the parameters.

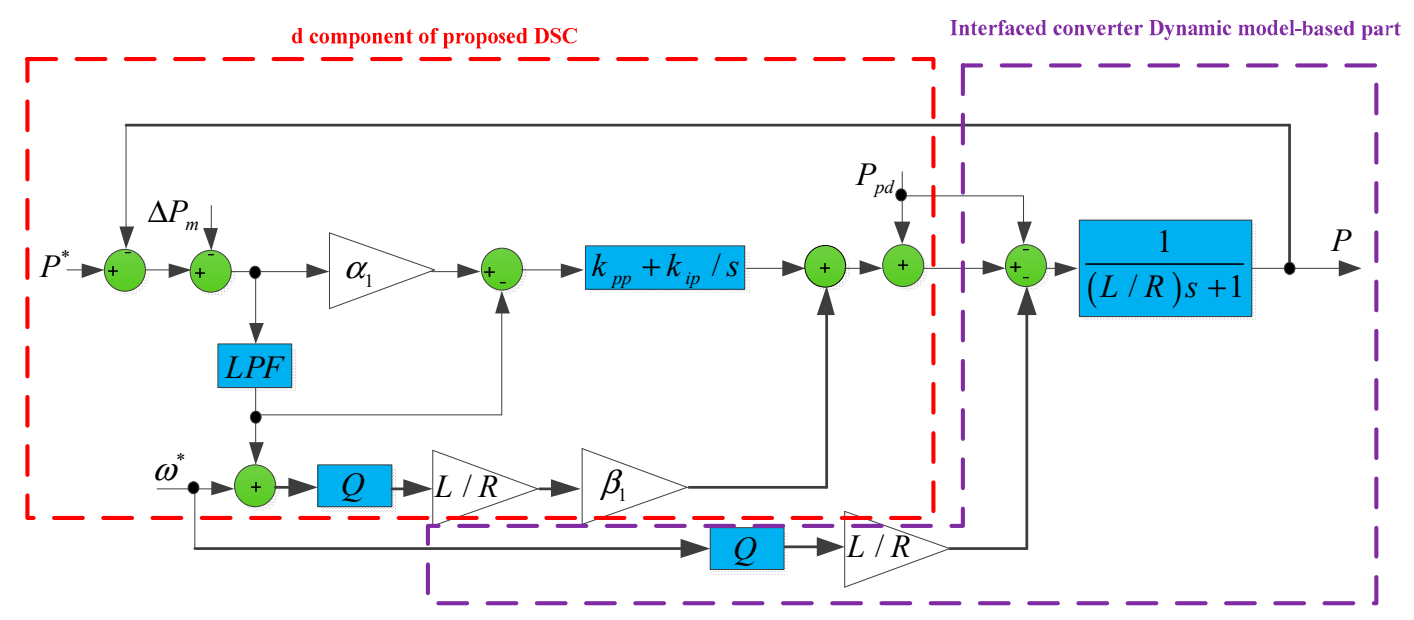

(a)

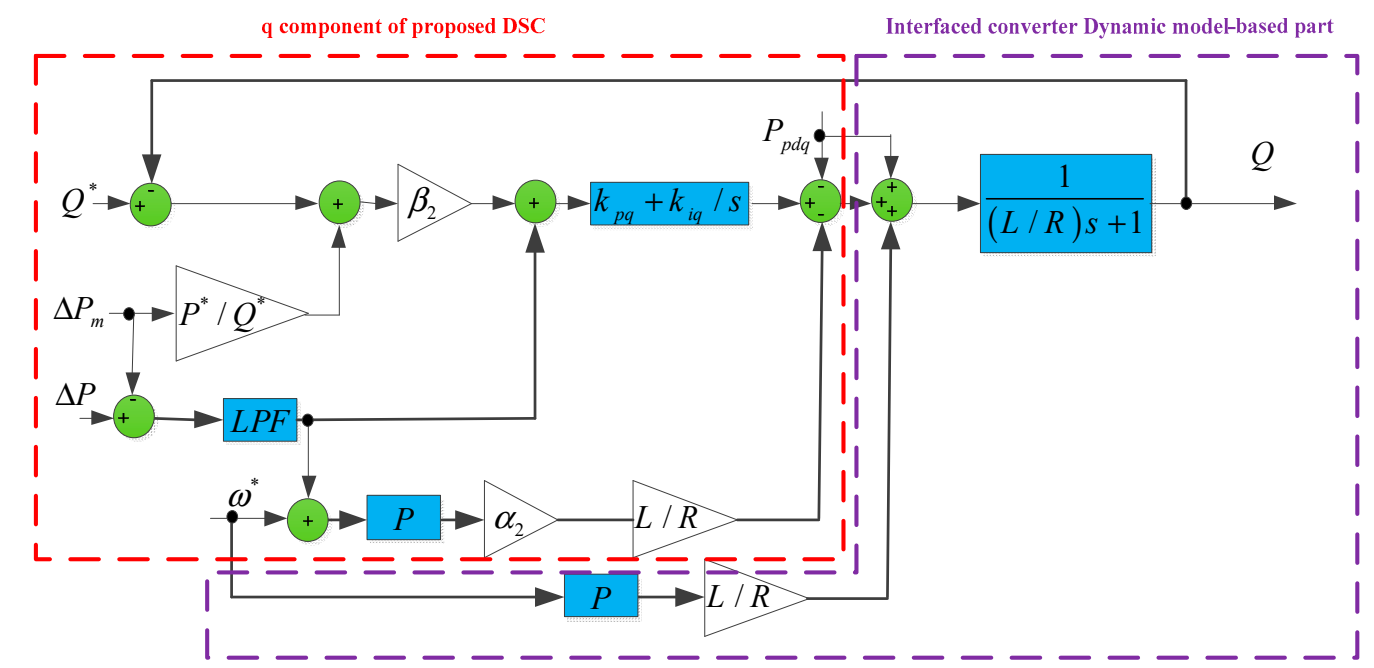

(b)

Figure 3. The proposed Double-Synchronous Controller (DSC): (a) d-component and (b) q-component. 


\section{The Comparison of the NSC and DSC Active and Reactive Power Error Curves}

In this section, two active and reactive power error curves are achieved for both NSC and DSC to analyze the related power errors and its stable operation. By applying small-signal linearization to two first terms of (2), it can meet:

$$
\begin{aligned}
& \frac{L}{R} s \Delta P+\Delta P+\frac{\Delta \omega L}{R} Q^{*}+\frac{\omega^{*} L}{R} \Delta Q-\Delta u_{d} P_{c 1}^{*}-u_{d}^{*} \Delta P_{c 1}+\Delta P_{d}=0 \\
& \frac{L}{R} s \Delta Q+\Delta Q-\frac{\Delta \omega L}{R} P^{*}-\frac{\omega^{*} L}{R} \Delta P+\Delta u_{q} P_{c 1}^{*}+u_{q}^{*} \Delta P_{c 1}-\Delta P_{d q}=0
\end{aligned}
$$

By combining (10) and (11), the error curve of the NSC's active and reactive power are given as,

$$
\left(\Delta P+a_{N S C}\right)^{2}+\left(\Delta Q+b_{N S C}\right)^{2}=R_{N S C}^{2}
$$

The center parameters and radius of (12) can be written as,

$$
\begin{aligned}
& a_{N S C}=\left(\frac{\Delta \omega P^{*} L-R \Delta u_{q} P_{c 1}^{*}-R u_{q}^{*} \Delta P_{c 1}+R \Delta P_{d q}}{2 \omega^{*} L}\right) \\
& b_{N S C}=\left(\frac{\Delta \omega L Q^{*}-R \Delta u_{d} P_{c 1}^{*}-R u_{d}^{*} \Delta P_{c 1}+R \Delta P_{d}}{2 \omega^{*} L}\right) \\
& R_{N S C}=\sqrt{\left(\frac{\Delta \omega L Q^{*}-R \Delta u_{d} P_{c 1}^{*}-R u_{d}^{*} \Delta P_{c 1}+R \Delta P_{d}}{2 \omega^{*} L}\right)^{2}+} \\
& \left.\qquad \frac{\Delta \omega P^{*} L-R \Delta u_{q} P_{c 1}^{*}-R u_{q}^{*} \Delta P_{c 1}+R \Delta P_{d q}}{2 \omega^{*} L}\right)^{2}
\end{aligned}
$$

The error curve for the DSC's active and reactive power is given as (14),

$$
\left(\Delta P+a_{D S C}\right)^{2}+\left(\Delta Q+b_{D S C}\right)^{2}=R_{D S C}^{2}
$$

The radius and center parameters of the DSC error curve are specified as,

$$
\begin{aligned}
R_{D S C}= & \begin{array}{l}
\left(\frac{\left(P_{m}^{*}-P^{*}\right) L Q^{*} \Delta \omega-\omega^{*} L Q^{*} \Delta P_{m}-R \omega^{* 2} J \Delta \omega Q^{*}-\omega^{* 3} J P^{*} L \Delta \omega}{2 \omega^{*} L Q^{*}}\right)^{2}+ \\
\left(\frac{L \omega^{*} P^{*} \Delta P_{m}-\omega^{* 3} J \Delta \omega L Q^{*}-L P^{*}\left(P_{m}^{*}-P^{*}\right) \Delta \omega+\omega^{* 2} J P^{*} R \Delta \omega}{2 L Q^{*} \omega^{*}}\right)^{2} \\
\left(\begin{array}{l}
\omega^{*} J L Q^{* 2} \Delta \omega^{2}-\omega^{*} J P_{c 1}^{*} Q^{*} R \Delta u_{d} \Delta \omega-\omega^{*} J Q^{*} R u_{d}^{*} \Delta P_{c 1} \Delta \omega \\
+\omega^{*} J Q^{*} R \Delta P_{d} \Delta \omega+\omega^{*} J P^{* 2} L \Delta \omega^{2} \\
-\omega^{*} J P^{*} R P_{c 1}^{*} \Delta u_{q} \Delta \omega-\omega^{*} J P^{*} R u_{q}^{*} \Delta P_{c 1} \Delta \omega+\omega^{*} J P^{*} R \Delta P_{d q} \Delta \omega
\end{array}\right) \\
Q^{*} L
\end{array} \\
a_{D S C}= & \left(\begin{array}{l}
\frac{\left(P_{m}^{*}-P^{*}\right) L Q^{*} \Delta \omega-\omega^{*} L Q^{*} \Delta P_{m}-R \omega^{* 2} J \Delta \omega Q^{*}-\omega^{* 3} J P^{*} L \Delta \omega}{2 \omega^{*} L Q^{*}} \\
2 L Q^{*} \omega^{*}
\end{array}\right)
\end{aligned}
$$

By noticing the error curve parameters of the DSC active and reactive power in (15), this point can be understood that both centers coordinate and radius are dependent on the angular frequency error and mechanical power error. 
For the same error values of all state variables in both the NSC and the DSC error curves given in (12) and (14) respectively, two curves are drawn in Figure 4. As can be seen, the NSC error curve is much larger than the DSC one. Thus, it is verified that using the NSC can lead to larger values for the active and reactive power error. In other words, the employed characteristics of SG in DSC can force the interfaced converter to generate the required active and reactive power with a significant smaller errors related to the NSC. The virtual mechanical power error modifications can affect the DSC error curve, according to Figure 5. Selecting various values for virtual inertia can make the DSC error curve to be altered, according to Figure 6 .

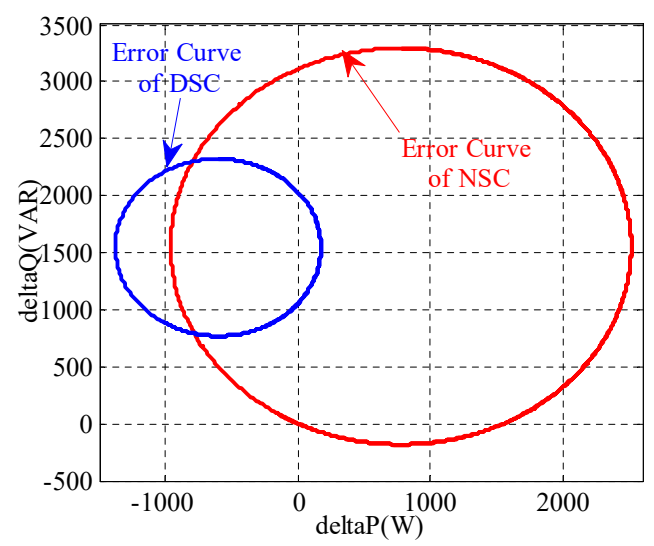

Figure 4. Error curves of active and reactive power for NSC and DSC.

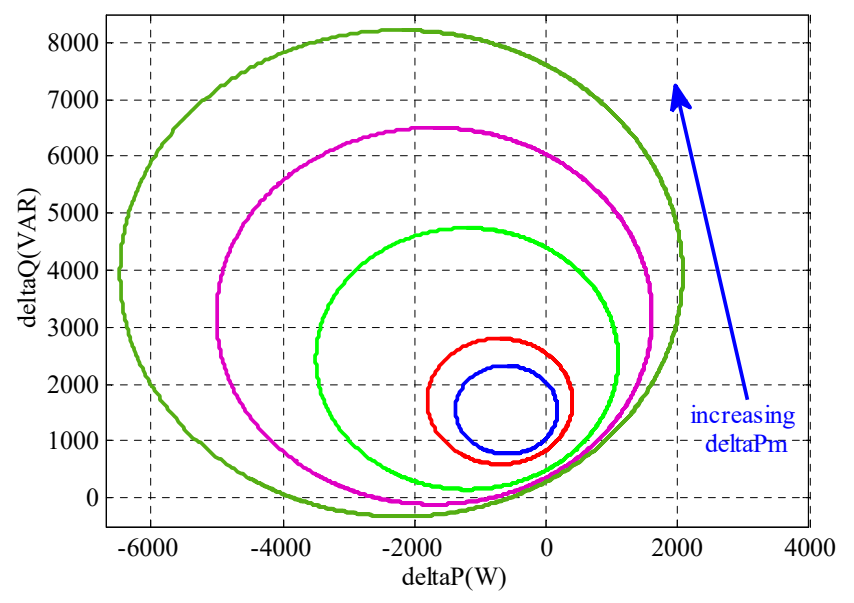

Figure 5. The effects of increasing $\Delta P_{m}$ on the DSC error curve.

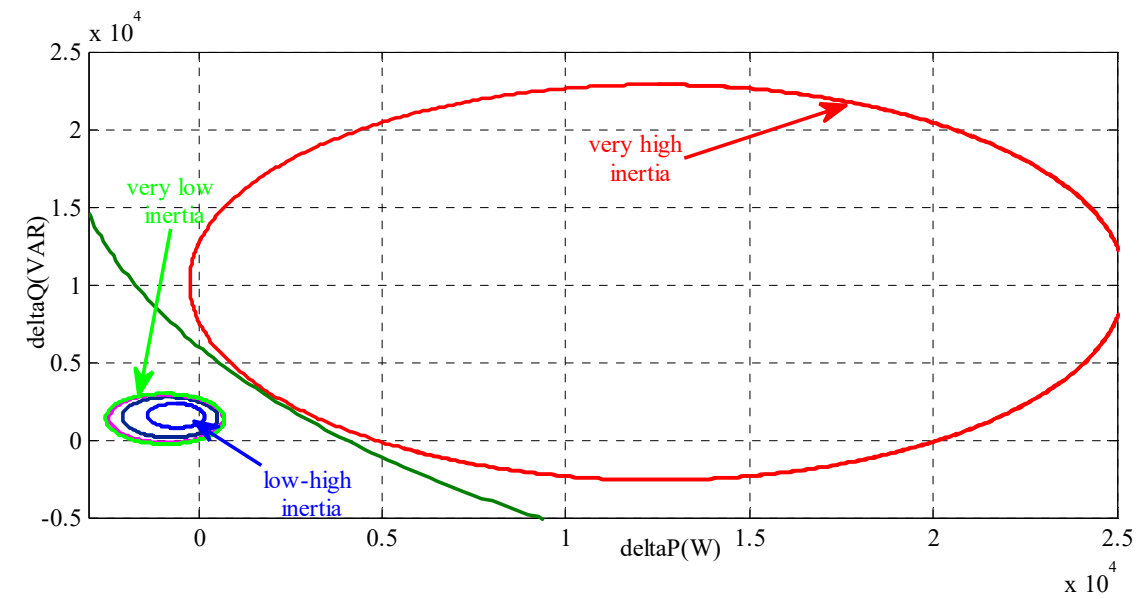

Figure 6. The consequences of varying virtual inertia (J) on DSC error curve. 


\section{The Power Sharing Capability}

In this section, the mathematical representations of the NSC and the DSC closed-loop models, given in Figures 2 and 3, respectively, are considered to analyze the ability of these controllers at tracking the reference values of active and reactive power. By referring to Figure 2, the relation between active and reactive power and their reference values for the NSC can be:

$$
\begin{gathered}
\frac{P}{P^{*}}=\frac{k_{p p} s+k_{i p}}{(L / R) s^{2}+\left(1+k_{p p}\right) s+k_{i p}} \\
\frac{Q}{Q^{*}}=\frac{k_{p q} s+k_{i q}}{(L / R) s^{2}+\left(1+k_{p q}\right) s+k_{i q}}
\end{gathered}
$$

Also, by using Figure 3, the relationship between active and reactive power and their reference values for the DSC can be achieved as (18) and (19):

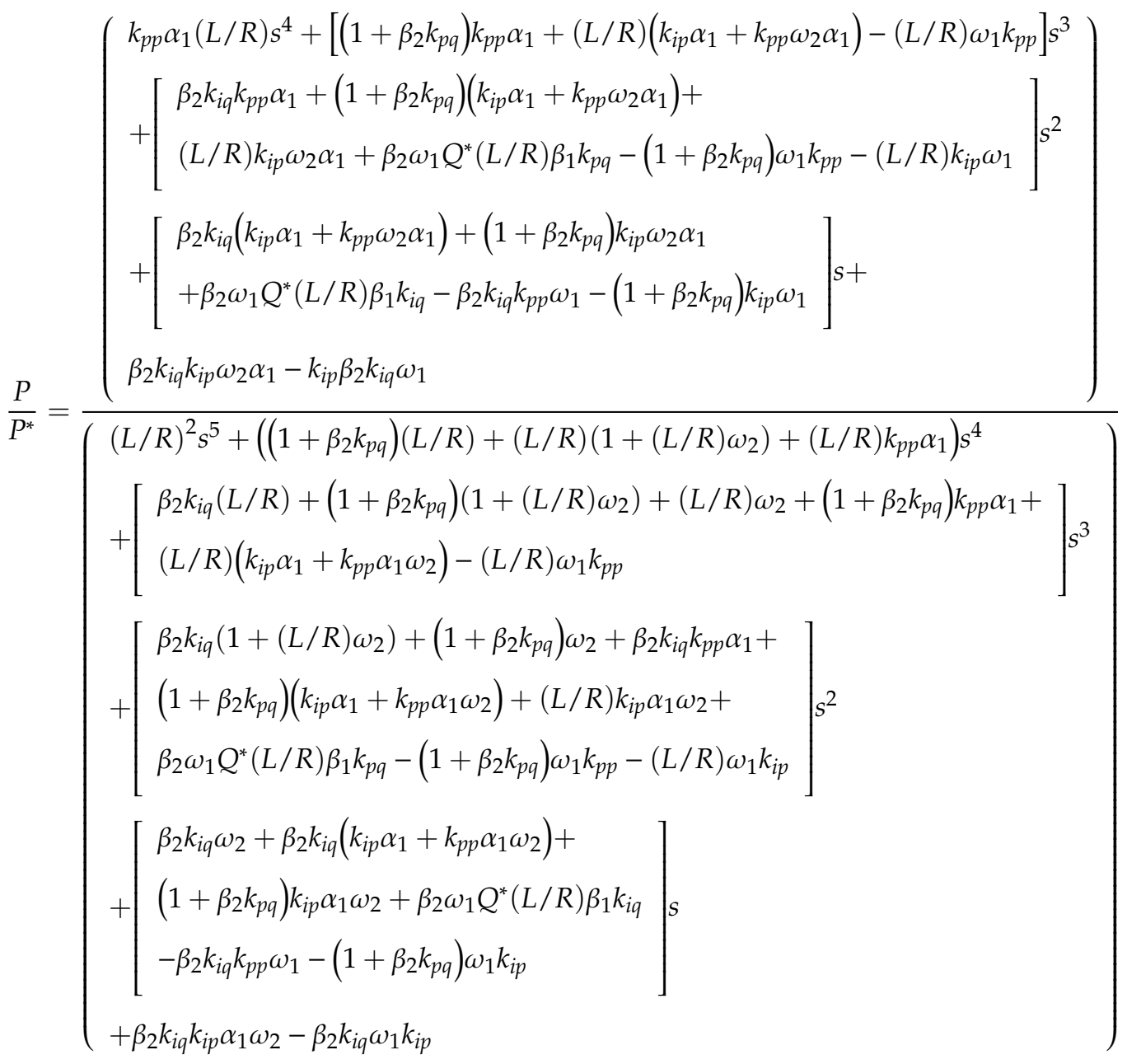

$$
\begin{aligned}
& \frac{Q}{Q^{*}}=\frac{\beta_{2}\left(k_{p q} s+k_{i q}\right)}{(L / R) s^{2}+\left(1+\beta_{2} k_{p q}\right) s+\beta_{2} k_{i q}}
\end{aligned}
$$


The Bode diagrams of Figure 7 ascertain more the aforementioned points. Notably, the angles of the DSC transfer functions for both active and reactive power are nearly equal to zero. However, this angle is about eight degrees for both active and reactive power of the NSC that leads to a decrease the precise performance of the NSC.

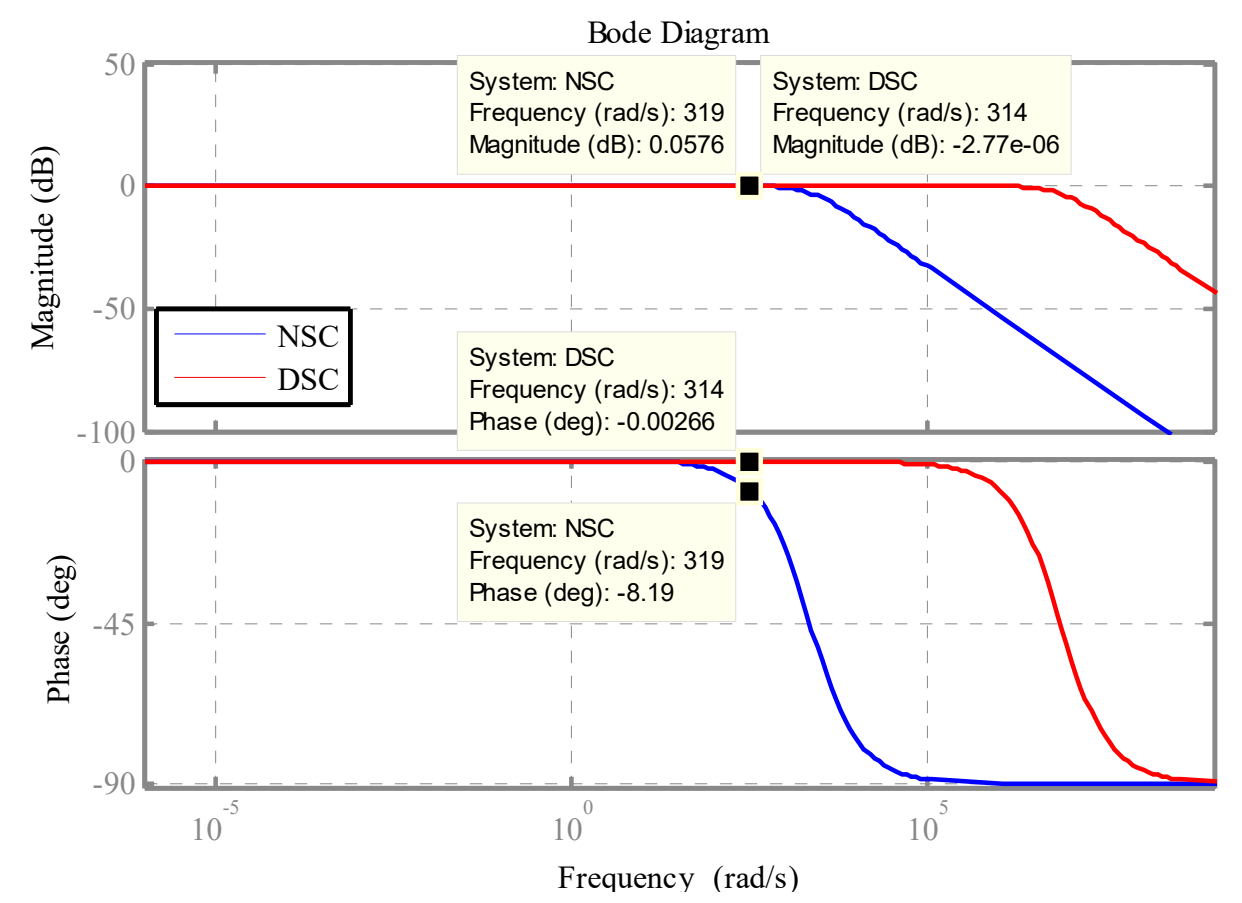

(a)

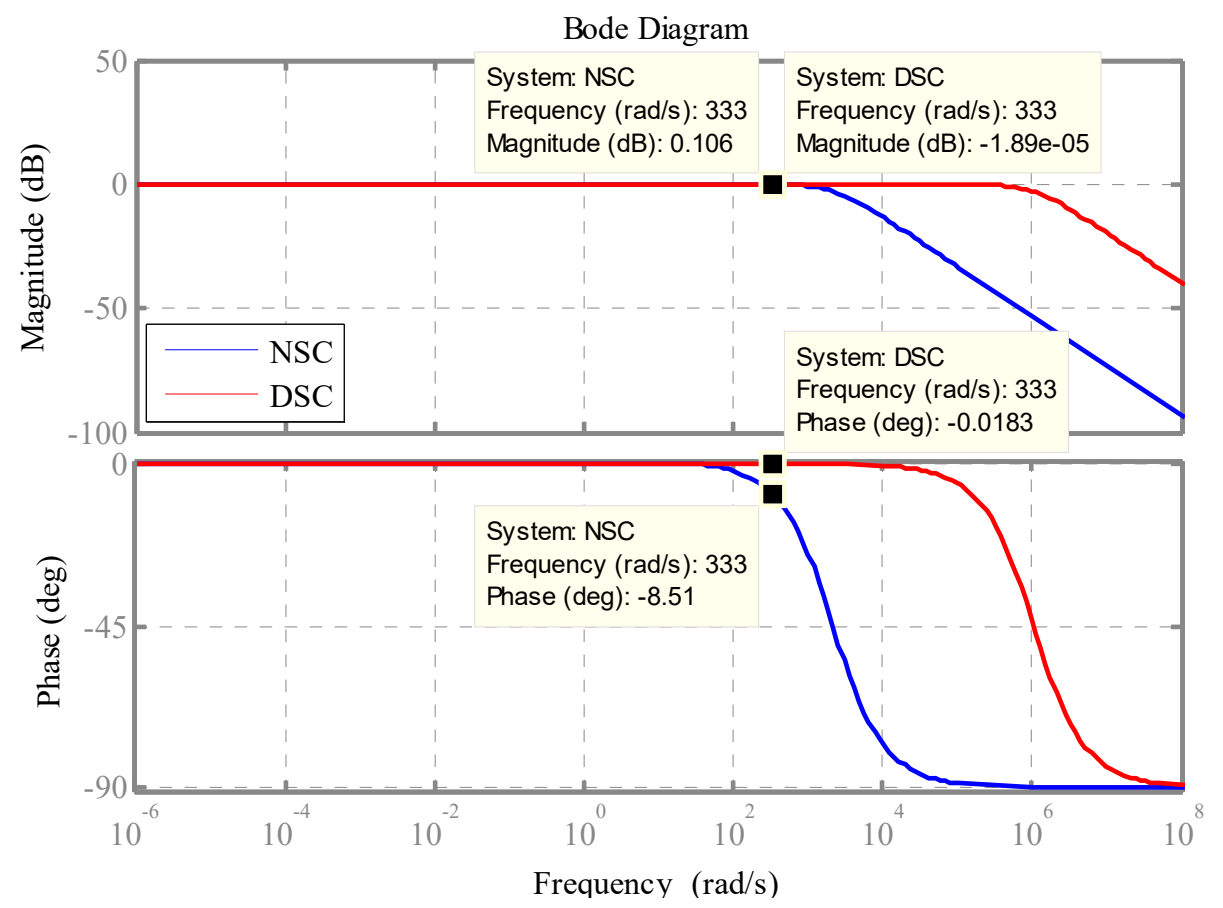

(b)

Figure 7. The Bode diagrams of: (a) $\mathrm{P} / \mathrm{P}^{*}$ and $(\mathbf{b}) \mathrm{Q} / \mathrm{Q}^{*}$ of the NSC and the DSC. 
Choosing various values for virtual inertia can impact on the performance of the power-sharing of the DSC that is investigated in this section. By considering the conditions of $\mathrm{J}_{1}>\mathrm{J}_{2}>\mathrm{J}_{3}>\mathrm{J}_{4}$, the Nyquist diagrams of $\mathrm{P} / \mathrm{P}^{*}$ and $\mathrm{Q} / \mathrm{Q}^{*}$ for the DSC are plotted, as shown in Figure 8.

It can be seen that the ability of the DSC to track the reference value of active power is noticeably decreased as the virtual inertia decreases. The negative effect of decreasing virtual inertia is more for reactive power, as shown in Figure 8b.

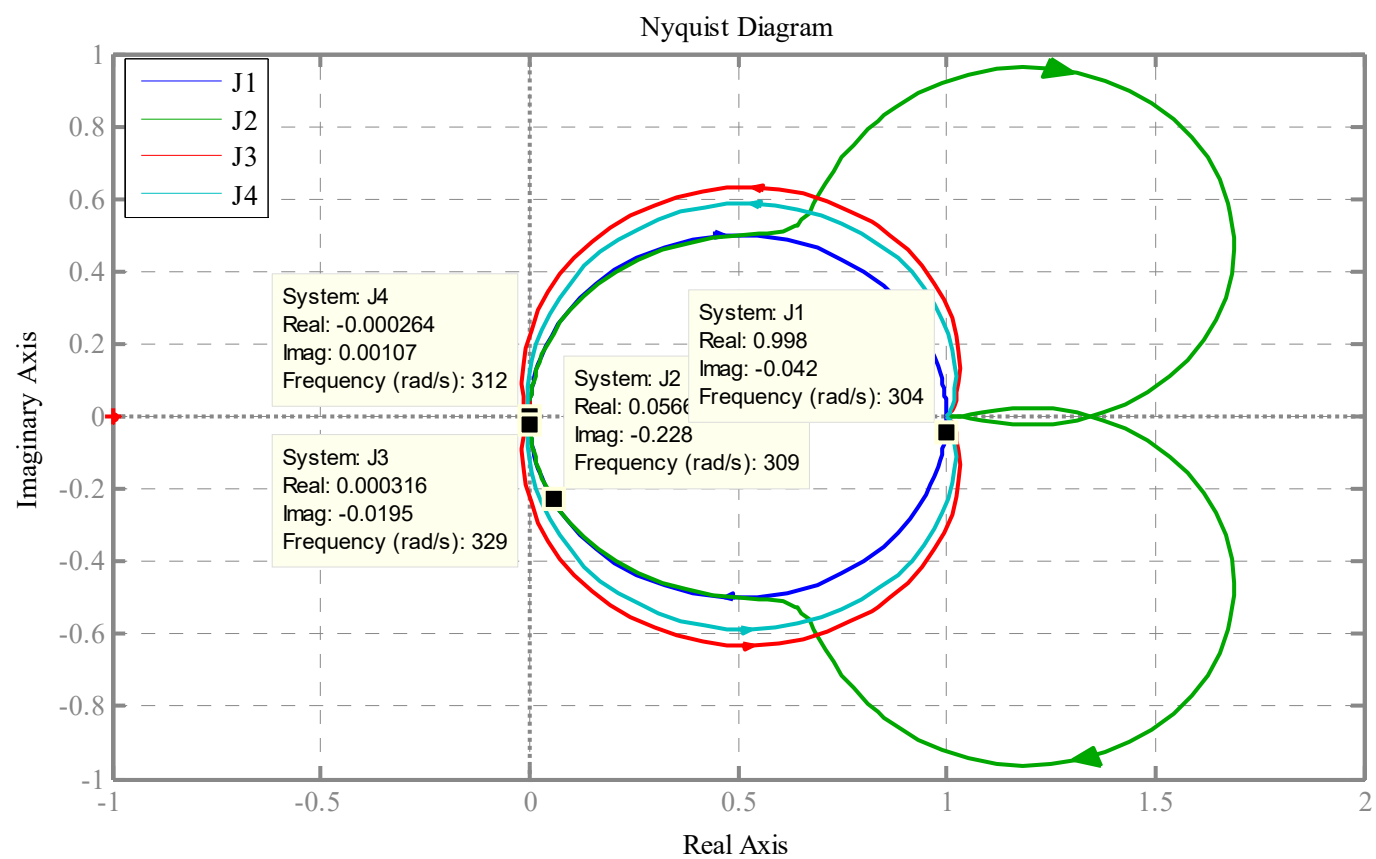

(a)

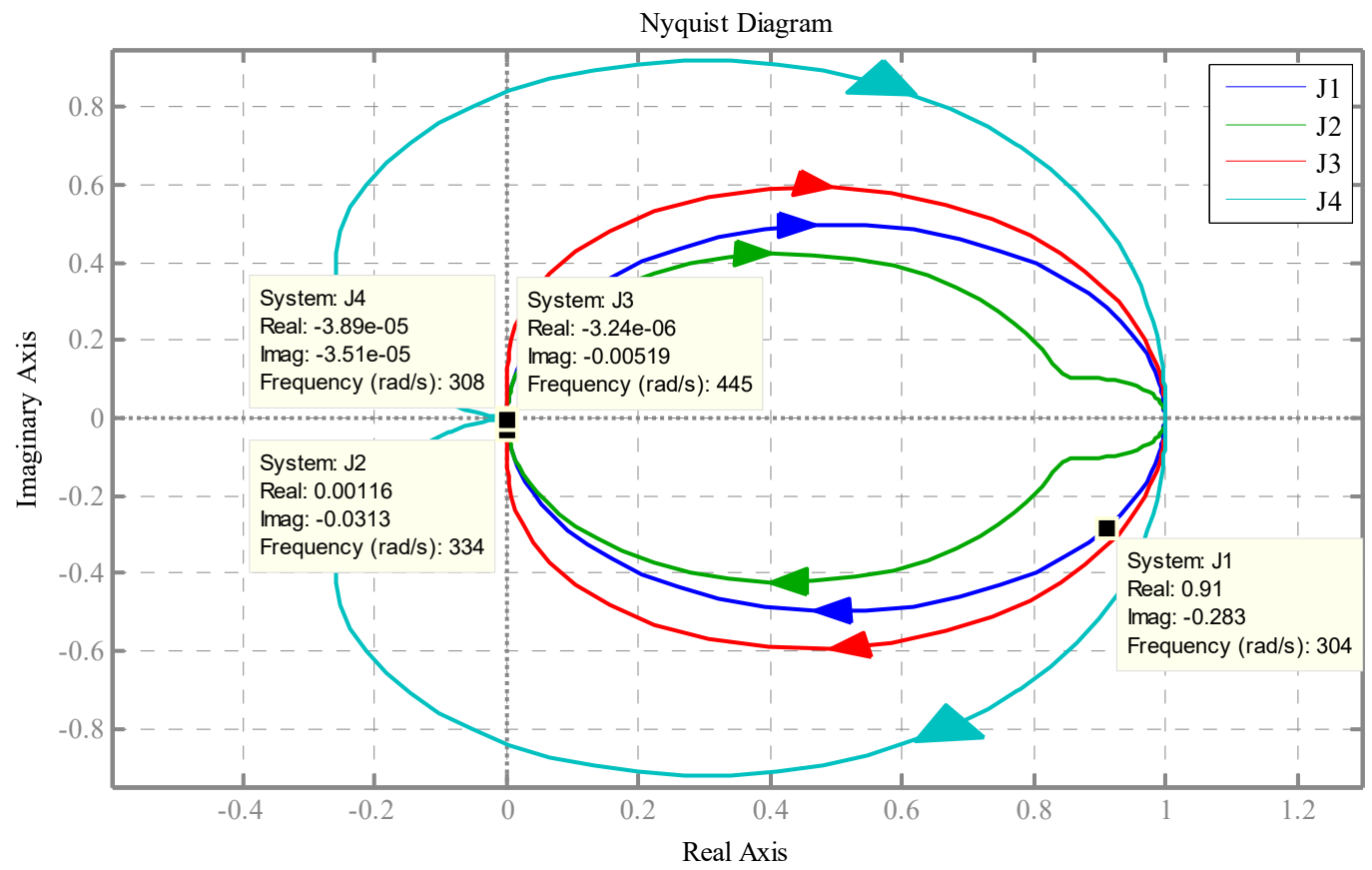

(b)

Figure 8. Various values of virtual inertia for the DSC: (a) $\mathrm{P} / \mathrm{P}^{*}$ and (b) $\mathrm{Q} / \mathrm{Q}^{*}$. 


\section{Angular Frequency Error Evaluation}

The other important issue related to the high penetration of renewable energy resources into the power grid is that how much the active and reactive power sharing can affect grid frequency regulation and vice versa. To accomplish an accurate analysis, this section is focusing on this issue. By using the two first terms of (2), the relationship between the angular frequency error and both active and reactive power error of the NSC can be achieved as:

$$
\Delta \omega=\frac{\left(\begin{array}{c}
\Delta Q^{2}+\left(\frac{-R \Delta u_{d} P_{c 1}^{*}-R u_{d}^{*} \Delta P_{c 1}+R \Delta P_{d}}{\omega^{*} L}\right) \Delta Q \\
+\Delta P^{2}+\left(\frac{-R \Delta u_{q} P_{c 1}^{*}-R u_{q}^{*} \Delta P_{c 1}+R \Delta P_{d q}}{\omega^{*} L}\right) \Delta P
\end{array}\right)}{-\left(\frac{L Q^{*} \Delta Q+P^{*} L \Delta P}{\omega^{*} L}\right)}
$$

By accomplishing the same process for (14) and (15), the relation between the angular frequency error and both active and reactive power errors of DSC are given by:

$$
\begin{gathered}
\Delta \omega=\sqrt{(\vartheta(\Delta P, \Delta Q))^{2}+\rho_{2} \Delta P^{2}+\rho_{1} \Delta P+\sigma_{2} \Delta Q^{2}+\sigma_{1} \Delta Q} \\
+\vartheta(\Delta P, \Delta Q) \\
\vartheta(\Delta P, \Delta Q)=\frac{\left(\begin{array}{l}
Q^{*} \omega^{* 2} J R \Delta u_{d} P_{c 1}^{*}+Q^{*} \omega^{* 2} J R u_{d}^{*} \Delta P_{c 1}-Q^{*} \omega^{* 2} J R \Delta P_{d}+\left(P_{m}^{*}-P^{*}\right) L Q^{*}-Q^{*} \omega^{* 2} J R-\omega^{* 3} J P^{*} L \Delta P+ \\
-\left(\omega^{* 3} J\right) L Q^{*} \Delta Q-L P^{*}\left(P_{m}^{*}-P^{*}\right) \Delta Q+\omega^{* 2} J P^{*} R \Delta Q+\omega^{* 2} J P^{*} R P_{c 1}^{*} \Delta u_{q}+\omega^{* 2} J P^{*} R u_{q}^{*} \Delta P_{c 1}-\omega^{* 2} J P^{*} R \Delta P_{d q}
\end{array}\right)}{2\left(L Q^{*} \omega^{*}\left(-\left(\omega^{*} J\right) Q^{*}-\left(\frac{\omega^{*} J P^{* 2}}{Q^{*}}\right)\right)\right)} \\
\rho_{2}=\frac{1}{\left(\left(\omega^{*} J\right) Q^{*}+\left(\frac{\omega^{*} J p^{* 2}}{Q^{*}}\right)\right)}, \rho_{1}=\left(\frac{\Delta P_{m}\left(L Q^{*} \omega^{*}\right)}{L Q^{*} \omega^{*}\left(-\left(\omega^{*} J\right) Q^{*}-\left(\frac{\omega^{*} J P^{* 2}}{Q^{*}}\right)\right)}\right), \sigma_{2}=\frac{1}{\left(\left(\omega^{*} J\right) Q^{*}+\left(\frac{\omega^{*} J p^{* 2}}{Q^{*}}\right)\right)}, \sigma_{1}=\frac{\left(\frac{L \omega^{*} P^{*} \Delta P_{m}}{L Q^{*} \omega^{*}}\right)}{\left(\left(\omega^{*} J\right) Q^{*}+\left(\frac{\omega^{*} J p^{* 2}}{Q^{*}}\right)\right)}
\end{gathered}
$$

The parameters in (21) are given at the footnote of the previous page. By noticing (21) and (22), it can be clearly seen that the angular frequency error is highly dependent on the values of the SG features, i.e., the virtual inertia, the mechanical power reference, and also the virtual mechanical power error. Thus, in the same operating conditions considered for the NSC and the DSC, the SG features can be regulated in order to decrease the angular frequency error as much as possible.

By the use of (20)-(22), the angular frequency error curves based on the active and reactive power error of the NSC and the DSC are drawn in Figure 9. According to Figure 9b, the simultaneous changes of the active and reactive power error can lead to the smaller angular frequency error compared to the NSC, as shown in Figure 9a. These results are achieved based on considering the same values for the same variables and parameters used in (20)-(22). Consequently, it can be understood that the better results of the proposed DSC are due to the embedded SG features. In further analysis of the DSC basic operation, the effects of the simultaneous changes of the angular frequency and virtual mechanical power error on active and reactive power errors of the DSC are shown in Figure 10. As can be seen, the smallest circle is driven though the smallest values of the angular frequency and virtual mechanical power error. On the other hand, the largest values of both angular frequency and virtual mechanical power error can lead to the worst response for the active and reactive power errors of the DSC, which is much more critical compared to the critical one in Figure 5. 


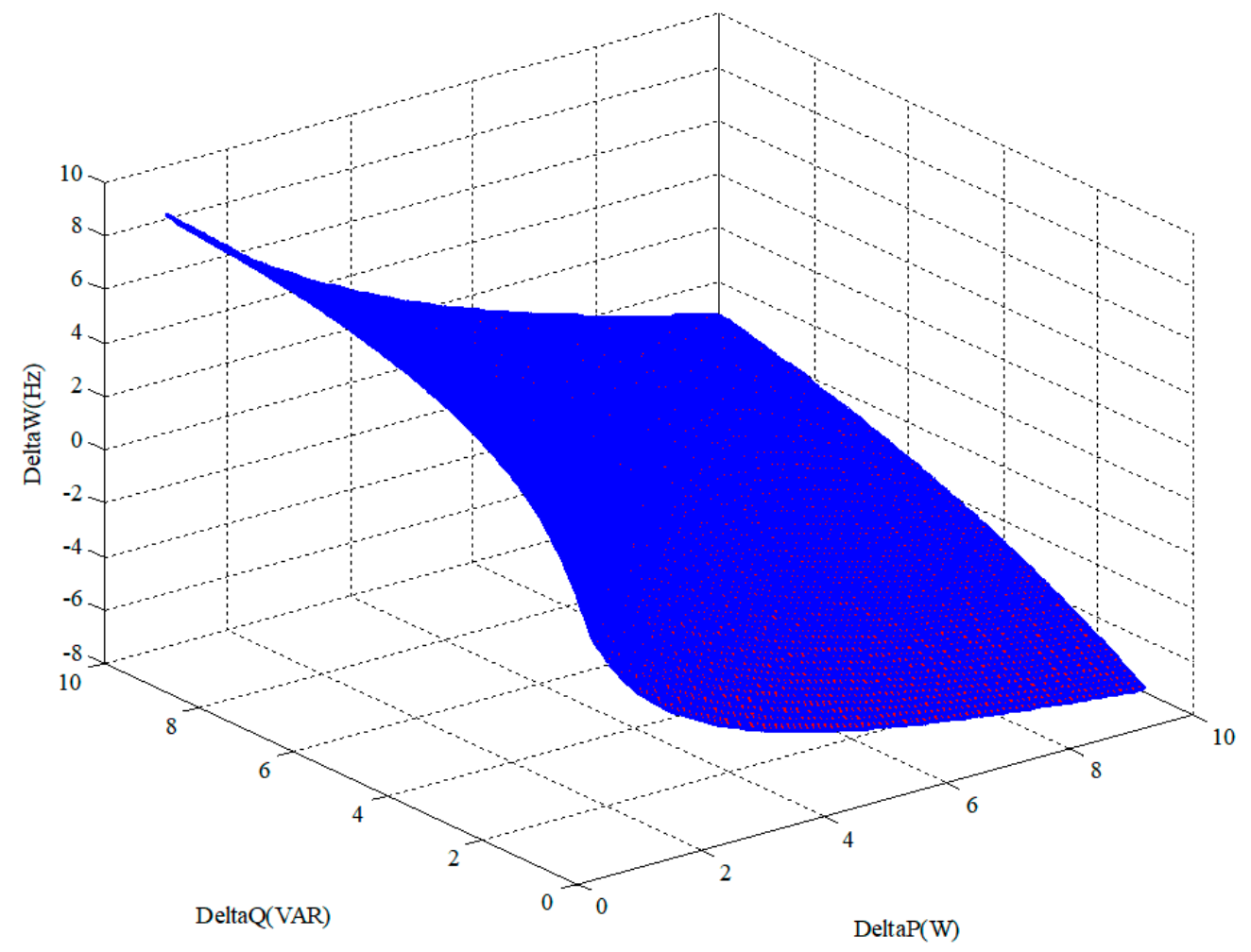

(a)

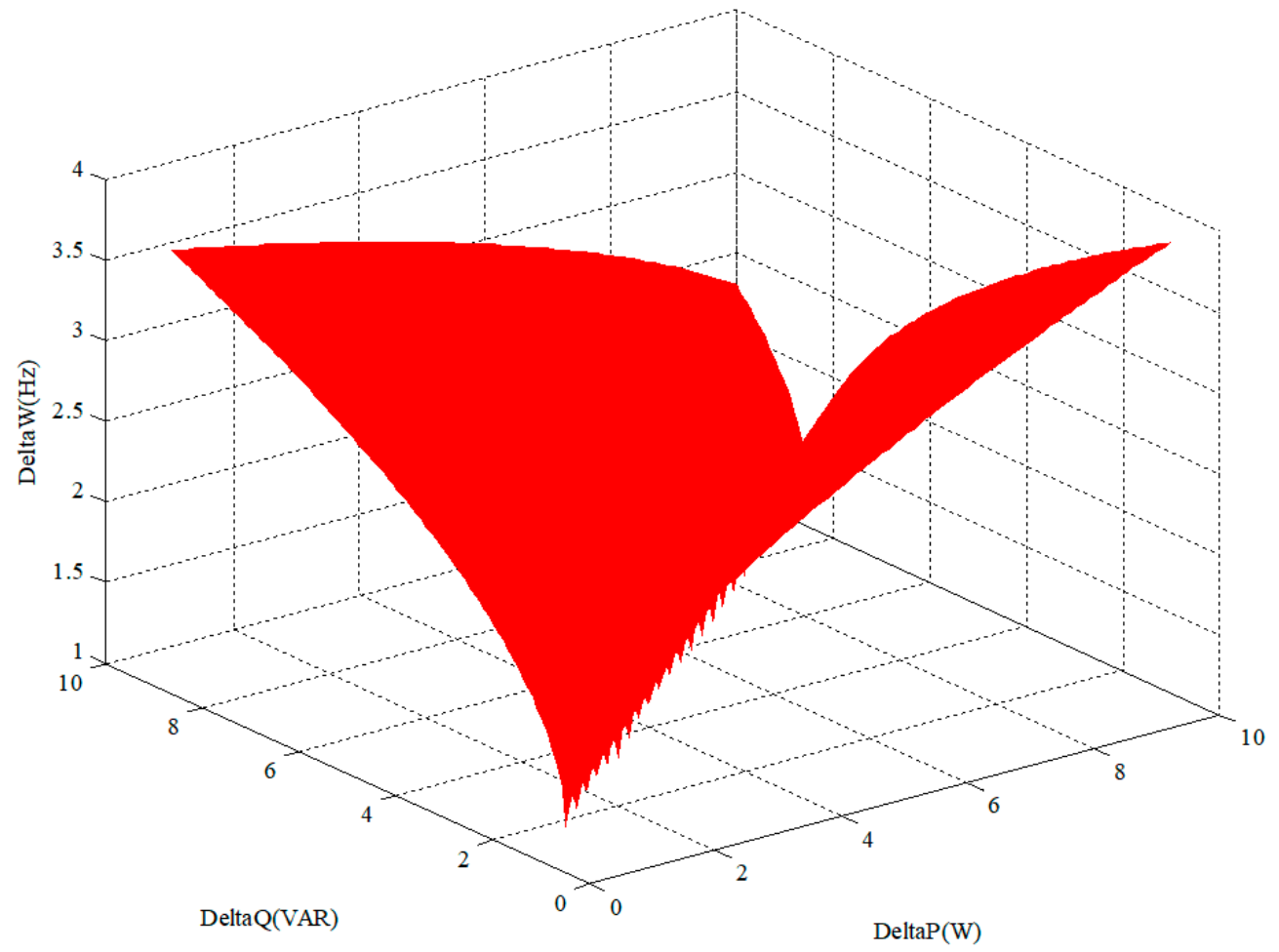

(b)

Figure 9. The angular frequency error curves based on the active and reactive power errors of (a): the NSC and (b): the DSC. 


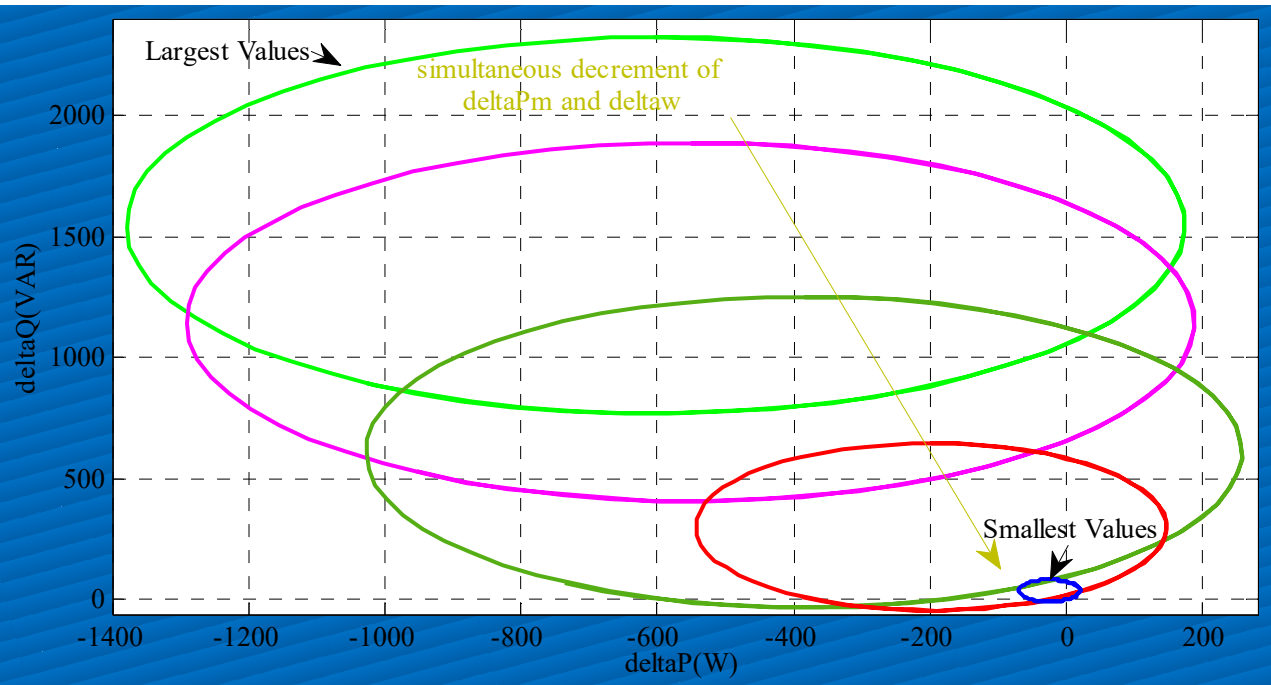

Figure 10. The simultaneous changes effects of the angular frequency and virtual mechanical power error on the DSC error curve.

\section{Results and Discussion}

Performance of both proposed control techniques, i.e., DSC and NSC, are compared in this section in MATLAB/SIMULINK environment to evaluate their operations in both steady-state and dynamic operating conditions. The parameters of the simulation are given in Table 1. Figure 11 shows the general structure of the grid under the high penetration of RERs through interfaced converters.

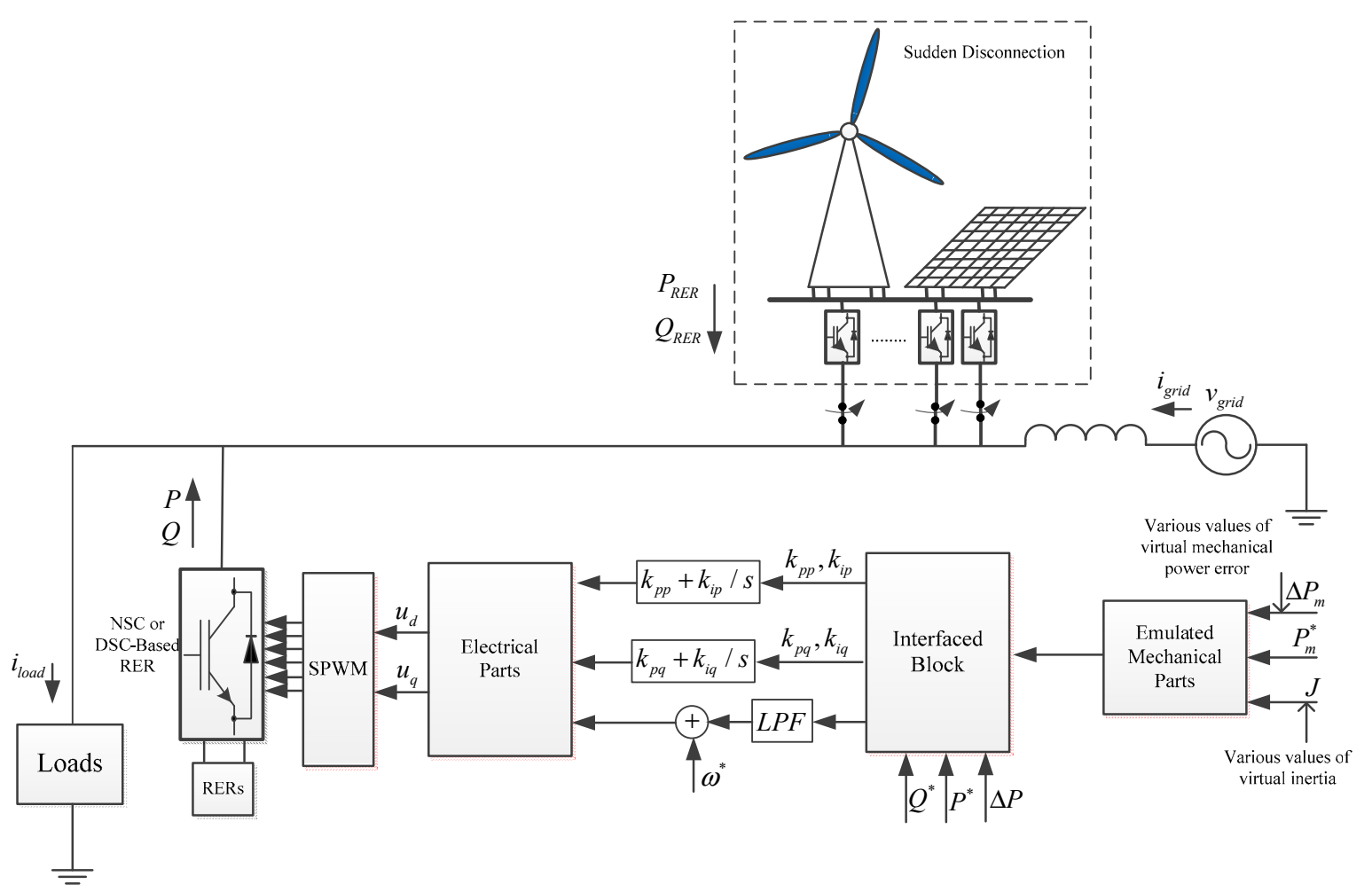

Figure 11. General structure of the proposed controllers for inertia emulation. 
Table 1. Simulation Parameters.

\begin{tabular}{cccc}
\hline Parameter & Value & Parameter & Value \\
\hline dc-link Voltage $\left(\mathrm{v}_{\mathrm{dc}}\right)$ & $850 \mathrm{~V}$ & $\mathrm{~J}_{1}$ & $1 \mathrm{e} 3 \mathrm{~s}$ \\
\hline Phase ac voltage & $220 \mathrm{~V}$ & $\mathrm{Pm}$ & $3.3 \mathrm{~kW}$ \\
\hline Fundamental frequency & $50 \mathrm{~Hz}$ & $\mathrm{P}$ & $3 \mathrm{~kW}$ \\
\hline Switching frequency & $10 \mathrm{kHz}$ & $\mathrm{Q}$ & $2 \mathrm{kVAr}$ \\
\hline Interfaced converter resistance (R1) & $0.1 \mathrm{Ohm}$ & Interfaced converter inductance (L1) & $45 \mathrm{mH}$ \\
\hline Interfaced converter resistance (R2) & $1 \mathrm{Ohm}$ & Interfaced converter inductance (L2) & $15 \mathrm{mH}$ \\
\hline
\end{tabular}

\subsection{Dynamic Analysis of the DSC vs. the NSC}

Firstly, supplying a $3 \mathrm{~kW}+\mathrm{j} 2 \mathrm{kvar}$ grid-connected load is performed by the NSC and DSC-based converter RERs. Then, a sudden disconnection of the PV sources with $4 \mathrm{~kW}+\mathrm{j} 3 \mathrm{KVar}$ happens at the PCC at $t=0.1$, which is not instantaneously supplied by the DSC and the NSC until $t=0.25 \mathrm{~s}$. After that, at $t=0.25$, both the DSC and the NSC start their responsibilities toward the power grid stability. In this sub-section, three RERs as power converter-based PV sources are used.

In this operating condition, the grid frequency of both the DSC and the NSC can be seen in Figure 12a. After a load increment at $t=0.1 \mathrm{~s}$, the DSC does not allow the grid frequency to have more overshoot than the NSC, as depicted in Figure 12a. It happens for the dynamic response of the DSC and the NSC grid frequency when both the proposed controllers operate at $t=0.25 \mathrm{~s}$, according to Figure 12a.

The grid voltage magnitude due to the DSC and the NSC during this dynamic condition can be observed in Figure 12b. As can be seen, the high damping properties of the DSC can help the grid voltage not to see any significant drop, especially, compared with the NSC. It causes a grid voltage magnitude of the DSC to be kept in an acceptable region. Also, the DSC is able to present a fast-dynamic response in its operation time at $t=0.25$ in which the grid voltage magnitude will follow its reference value with a slight transient response. Furthermore, the NSC does not have a fast-dynamic response in comparison with the DSC, and also it is not able to reach its desired value after $t=0.25 \mathrm{~s}$, as shown in Figure 12b.

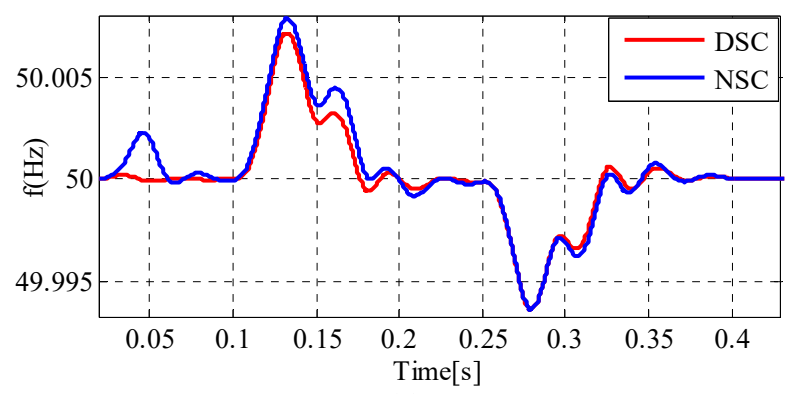

(a)

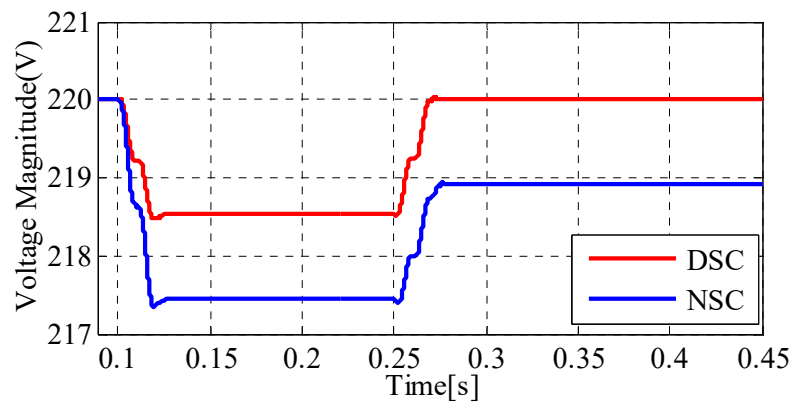

(b)

Figure 12. Comparison between the DSC and the NSC during disconnection of RER penetration: (a) grid frequency, and (b) grid voltage magnitude. 


\subsection{Impacts of Virtual Mechanical Power Error (VMPE) on Operation of the DSC}

Selecting different values of VMPE in the DSC can affect the power grid stability. Figure 13 shows the grid frequency and the grid voltage magnitude of the DSC under three low, high, and very high values of VMPE. As can be seen in Figure 13, for the low values of the VMPE, accurate results are achieved for both state variables. According to Figure 13a,b, the unstable behaviors of the grid frequency and grid voltage magnitude reactions for these very high values of VMPE are obvious. Simulation results demonstrated that the VMPE and inertia effectively impact on the operation of the DSC. Also, for high values of VMPE, both steady-state and dynamic responses of all state variables can follow their desired values with a different margin that generally is superior for the DSC compared with the case due to various values of virtual inertia.

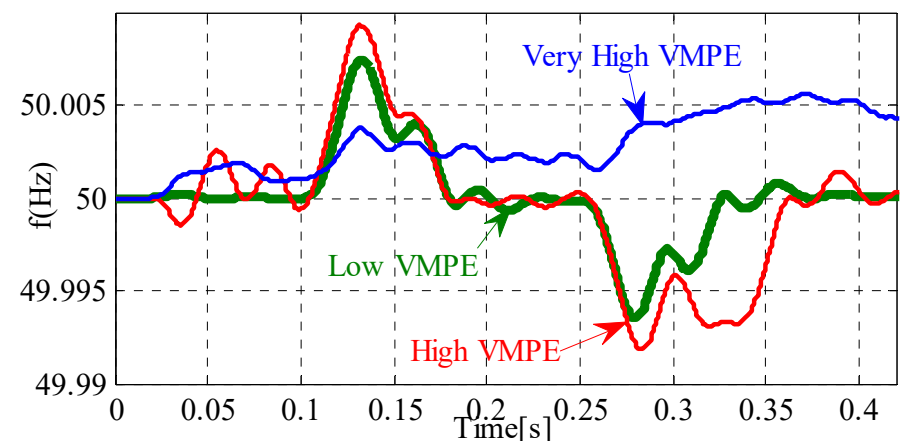

(a)

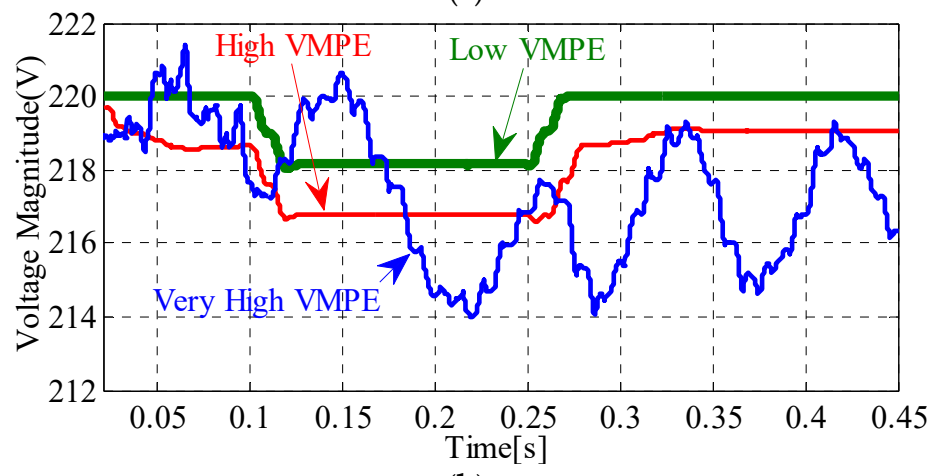

(b)

Figure 13. VMPE values in the DSC: (a) grid frequency, and (b) grid voltage magnitude.

\subsection{Impacts of Parameter Variations on Operation of the DSC and NSC}

Some variations on parameters $\mathrm{R}$ and $\mathrm{L}$ are considered at $t=0.15 \mathrm{~s}$. It can be seen from Figure 14 that no significant changes happen on grid frequency and voltage magnitude when the proposed DSC is employed to the grid-connected interfaced converter. Also, by noticing to Figure 14, it can be understood that the proposed DSC has a significant superiority in both steady-state and transient operating conditions under the parameters variations in comparison with the performance of the NSC in the same operating conditions. 


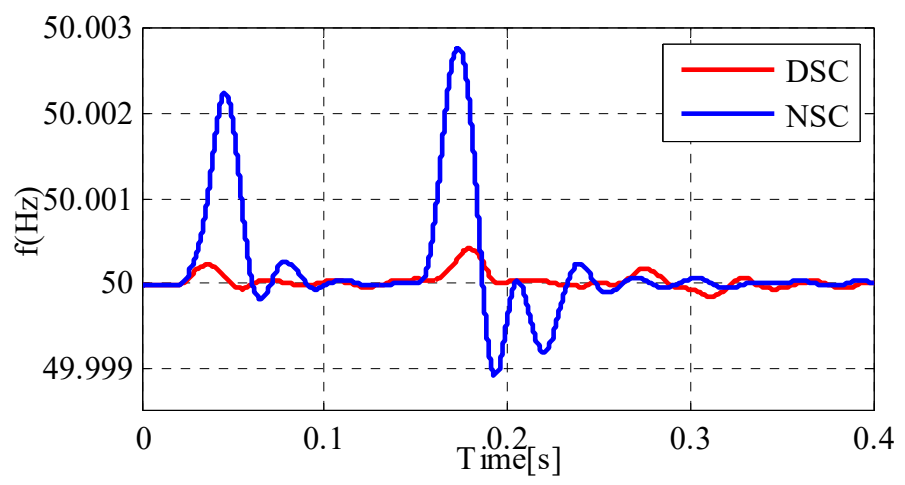

(a)

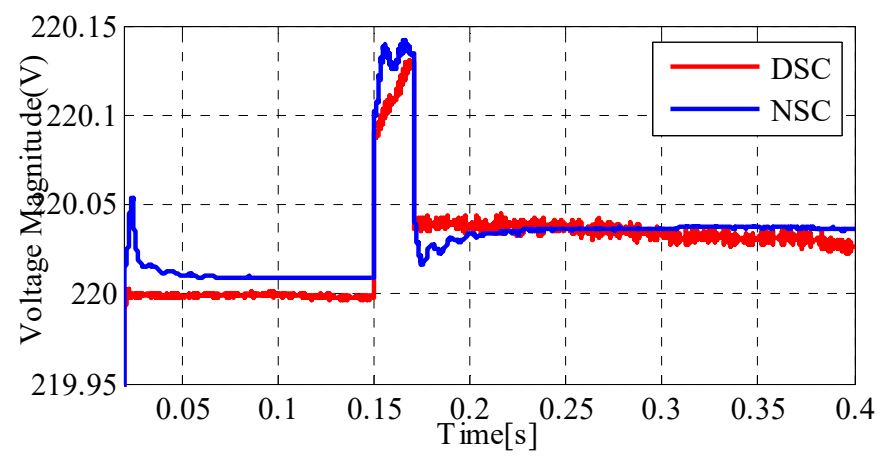

(b)

Figure 14. Parameters variations effects on DSC and NSC: (a) grid frequency, and (b) grid voltage magnitude.

\section{Conclusions}

A double synchronous controller (DSC) was projected for the interfaced converters between renewable energy resources (RERs) and the power grid. The proposed controller is based on the emulated features of SGs, i.e., inertia, virtual mechanical power reference, and virtual mechanical power error, to guarantee the stable operation of the power grid under high penetration of RERs. Using a more comprehensive relationship between the interfaced converter and SGs dynamic models along with more detailed features of SGs have been major contributions of the proposed DSC in comparison with other similar existing methods. Other contributions have been to provide more decoupling features for both $\mathrm{d}$ and $\mathrm{q}$ components that are completely involved with SGs characteristics as well as robustness against the unknown intrinsic property of parameters. The operation of the proposed DSC has been compared with a non-synchronous controller (NSC) to confirm the high performance of the DSC in the control of the interfaced converters in the power system. Moreover, a comprehensive stability analysis of the DSC power sharing capability along with its flexible regulation of both grid frequency and voltage magnitude has been executed. Obtained results confirm that the proposed DSC can behave as a power electronics-based synchronous generator for the integration of large-scale RERs into the power grid.

Author Contributions: Conceptualization, M.M., E.P.; Methodology, M.M.; Software, M.M.; Validation, M.M., E.P.; Formal Analysis, M.M., E.P.; Investigation, M.M.; Resources, E.P., H.S., F.B., M.R.A.C. and J.P.S.C.; Writing-Original Draft Preparation M.M.; Writing-Review \& Editing, E.P., H.S., F.B., M.R.A.C. and J.P.S.C.; Visualization, H.S.; Supervision, E.P., M.R.A.C. and J.P.S.C.

Funding: J.P.S.C. acknowledges the support by FEDER funds through COMPETE 2020 and by Portuguese funds through FCT, under POCI-01-0145-FEDER-029803 (02/SAICT/2017).

Conflicts of Interest: The authors declare no conflict of interest. 


\section{Nomenclatures}

\section{Abbreviation}

RERs

Renewable Energy Resources

VMP Virtual Mechanical Power

DSC Double Synchronous Controller

SG Synchronous Generator

DESS Distributed Energy Storage System

VSM Virtual Synchronous Machine

PV Photovoltaic

PCC Point of Common Coupling

LPF Low Pass Filter

\section{Variables}

$i_{d q}$

$v_{d q}$

$v_{d c}$

$u_{d q}$

$i_{d c}$

$P$

$Q$

$P_{c 2}$

$P_{d}$

$P_{d q}$

$P_{m}$

$\omega$

$\Delta \mathrm{P}$

$\Delta \mathrm{P}_{\mathrm{m}}$

$\Delta \omega$

$\Delta \mathrm{Q}$

$P^{*}$

$\mathrm{P}_{\mathrm{m}}$ *

$\omega^{*}$

Currents of Converter in dq reference frame

Voltages at PCC in dq reference frame

dc-Link Voltage

Switching Functions

dc-Link Current

The Active Power of an interfaced converter

The Reactive Power of interfaced converter

dc-Link Current Based Power

d-Component Power

Combined Power

Mechanical Power

Angular Frequency

Active Power Error

VMP Error

Angular Frequency Error

Reactive Power Error

Reference Active Power

Reference VMP

Parameters

L

Reference Angular Frequency

$R$

The Inductance of an interfaced converter

The Resistance of interfaced converter

$C \quad$ DC-Link Capacitor

$J \quad$ Virtual Inertia

$\omega_{1}, \omega_{2} \quad$ LPF Coefficients

$k_{p p}, k_{i p} \quad$ The Controller Coefficients of Active Power Component

$\mathrm{k}_{\mathrm{pq}}, \mathrm{k}_{\mathrm{iq}} \quad$ The Controller Coefficients of Reactive Power Component

$\alpha_{1(2)}, \beta_{1(2)} \quad$ Decoupled Factors of Closed- Loop Descriptions

\section{References}

1. Lund, H.; Mathiesen, B.V. Energy system analysis of $100 \%$ renewable energy systems-The case of Denmark in years 2030 and 2050. Energy 2009, 34, 524-531. [CrossRef]

2. Miller, N.; Loutan, C.; Shao, M.; Clark, K. Emergency response: US system frequency with high wind penetration. IEEE Power Energy Mag. 2013, 11, 63-71. [CrossRef]

3. Mehrasa, M.; Pouresmaeil, E.; Mehrjerdi, H.; Jørgensen, B.N.; Catalão, J.P.S. Control technique for enhancing the stable operation of distributed generation units within a microgrid. Energy Convers. Manag. 2015, 97, 362-373. [CrossRef]

4. Mehrasa, M.; Pouresmaeil, E.; Jørgensen, B.N.; Catalão, J.P.S. A control plan for the stable operation of microgrids during grid-connected and islanded modes. Electr. Power Syst. Res. 2015, 129, 10-22. [CrossRef] 
5. Guerrero, J.M.; Chandorkar, M.; Lee, T.; Loh, P.C. Advanced control architectures for intelligent microgrids-Part I: Decentralized and hierarchical control. IEEE Trans. Ind. Electr. 2013, 60, 1254-1262. [CrossRef]

6. Holari, Y.T.; Taher, S.A.; Mehrasa, M. Distributed energy storage system-based nonlinear control strategy for hybrid microgrid power management included wind/PV units in grid-connected operation. Electr. Energy Syst. 2019. [CrossRef]

7. Mehrasa, M.; Sharifzadeh, M.; Al-Haddad, K. A droop based-control strategy of stand-alone single-phase converters for microgrid applications. In Proceedings of the IECON 2018-44th Annual IEEE Conference, Washington, DC, USA, 21-23 October 2018; pp. 5261-5266.

8. Hosseini, S.M.; Carli, R.; Dotoli, M. Robust day-ahead energy scheduling of a smart residential user under uncertainty. In Proceedings of the 18th European Control Conference (ECC), Naples, Italy, 25-28 June 2019.

9. Carli, R.; Dotoli, M. Decentralized control for residential energy management of a smart users microgrid with renewable energy exchange. IEEE/CAA J. Autom. Sin. 2019, 6, 641-656. [CrossRef]

10. Geidl, M.; Koeppel, G.; Favre-Perrod, P.; Klockl, B.; Andersson, G.; Frohlich, K. Energy hubs for the future. IEEE Power Energy Mag. 2007, 5, 24-30. [CrossRef]

11. Rocabert, J.; Luna, A.; Blaabjerg, F.; Rodriguez, P. Control of power converters in ac microgrids. IEEE Trans. Power Electr. 2012, 27, 4734-4749. [CrossRef]

12. Majumder, R. Reactive power compensation in single-phase operation of microgrid. IEEE Trans. Ind. Electr. 2013, 60, 1403-1416. [CrossRef]

13. Pathak, A.K.; Sharma, M.P.; Gupta, M. Modeling and simulation of SVC for reactive power control in high penetration wind power system. In Proceedings of the 2015 Annual IEEE India Conference (INDICON), New Delhi, India, 17-20 December 2015; pp. 1-6.

14. Miranda, I.; Silva, N.; Leite, H. A holistic approach to the integration of battery energy storage systems in island electric grids with high wind penetration. IEEE Trans. Sustain. Energy 2016, 7, 775-785. [CrossRef]

15. Fang, J.; Tang, Y.; Li, H.; Li, X. A battery/ultracapacitor hybrid energy storage system for implementing the power management of virtual synchronous generators. IEEE Trans. Power Electr. 2018, 33, 2820-2824. [CrossRef]

16. Sperstad, I.B.; Korpås, M. Energy storage scheduling in distribution systems considering wind and photovoltaic generation uncertainties. Energies 2019, 12, 1231. [CrossRef]

17. Zeraati, M.; Golshan, M.E.H.; Guerrero, J.M. Distributed control of battery energy storage systems for voltage regulation in distribution networks with high PV penetration. IEEE Trans. Smart Grid 2016, 9, 3582-3593. [CrossRef]

18. Rubino, S.; Mazza, A.; Chicco, G.; Pastorelli, M. Advanced control of inverter-interfaced generation behaving as a virtual synchronous generator. In Proceedings of the 2015 IEEE Eindhoven PowerTech, Eindhoven, North Brabant, The Netherlands, 29 June-2 July 2015; pp. 1-6.

19. Lu, S.; Xu, Z. A novel control strategy of VSC-HVDC for offshore platforms. In Proceedings of the 12th IET International Conference, ACDC2016, Beijing, China, 28-29 May 2016; pp. 1-6.

20. Wang, Y.; Xu, Y.; Tang, Y. Distributed aggregation control of grid-interactive smart buildings for power system frequency support. Appl. Energy. 2019, 251, 113371. [CrossRef]

21. Wang, Y.; Tang, Y.; Xu, Y.; Xu, Y.L. A distributed control scheme of thermostatically controlled loads for the building-microgrid community. IEEE Trans. Sustain. Energy. Early Access 2019. [CrossRef]

22. Zhong, Q.C.; Weiss, G. Synchronverters: Inverters that mimic synchronous generators. IEEE Trans. Ind. Electr. 2011, 58, 1259-1267. [CrossRef]

23. Alipoor, J.; Miura, Y.; Ise, T. Stability assessment and optimization methods for microgrid with multiple VSG units. IEEE Trans. Smart Grid 2016, 9, 1462-1471. [CrossRef]

24. Torres, M.A.; Lopes, L.A.; Moran, L.A.; Espinoza, J.R. Self-tuning virtual synchronous machine: A control strategy for energy storage systems to support dynamic frequency control. IEEE Trans. Energy Convers. 2014, 29, 833-840. [CrossRef]

25. Guan, M.; Pan, W.; Zhang, J.; Hao, Q.; Cheng, J.; Zheng, X. Synchronous generator emulation control strategy for voltage source converter (VSC) stations. IEEE Trans. Power Syst. 2015, 30, 3093-3101. [CrossRef]

26. Ma, Y.; Cao, W.; Yang, L.; Wang, F.; Tolbert, L.M. Virtual synchronous generator control of full converter wind turbines with short term energy storage. IEEE Trans. Ind. Electr. 2017, 64, 8821-8831. [CrossRef] 
27. Pulendran, S.; Tate, J.E. Hysteresis control of voltage source converters for synchronous machine emulation. In Proceedings of the PEMC 2012, Novi Sad, Vojvodina, Serbia, 4-6 September 2012; pp. LS3b.2-1-LS3b.2-8.

28. Yang, L.; Wang, J.; Ma, Y.; Wang, J.; Zhang, X.; Tolbert, L.M.; Wang, F.; Tomsovic, K. Three-phase power converter-based real-time synchronous generator emulation. IEEE Trans. Power Electr. 2017, 32, 1651-1665. [CrossRef]

29. Liu, J.; Miura, Y.; Ise, T. Comparison of dynamic characteristics between virtual synchronous generator and droop control in inverter-based distributed generator. IEEE Trans. Power Electr. 2016, 31, 3600-3611. [CrossRef]

30. Pouresmaeil, E.; Mehrasa, M.; Godina, R.; Vechiu, I.; Rodríguez, R.L.; Catalão, J.P.S. Double synchronous controller for integration of large-scale renewable energy sources into a low-inertia power grid. In Proceedings of the IEEE PES Innovative Smart Grid Technologies Conference Europe (ISGT-Europe), Politecnico di Torino, Torino, Italy, 26-29 September 2017.

31. Mehrasa, M.; Pouresmaeil, E.; Marzband, M.; andCatalão, J.P.S. A single synchronous controller for high penetration of renewable energy resources into the power grid. In Proceedings of the IEEE International Conference (EEEIC/I\&CPS Europe), Palermo, di Palermo, Italy, 12-15 June 2018.

32. Mehrasa, M.; Pouresmaeil, E.; Soltani, H.; Blaabjerg, F.; Calado, M.R.A.; Catalão, J.P.S. Virtual inertia and mechanical power-based control strategy to provide stable grid operation under high renewables penetration. Appl. Sci. 2019, 9, 1043. [CrossRef]

33. Mehrasa, M.; Sepehr, A.; Pouresmaeil, E.; Marzband, M.; Catalão, J.P.S.; Kyyrä, J. Stability analysis of a synchronous generator-based control technique used in large-scale grid integration of renewable energy. In Proceedings of the International Conference on Smart Energy Systems and Technologies (SEST), Sevilla, Spain, 10-12 September 2018; pp. 1-5.

34. Mehrasa, M.; Sepehr, A.; Pouresmaeil, E.; Kyyrä, J.; Marzband, M.; Catalão, J.P.S. Angular frequency dynamic-based control technique of a grid-interfaced converter emulated by a synchronous generator. In Proceedings of the International Conference on Smart Energy Systems and Technologies (SEST), Sevilla, Spain, 10-12 September 2018; pp. 1-5.

35. Mehrasa, M.; Pouresmaeil, E.; Sepehr, A.; Pournazarian, B.; Catalão, J.P.S. Control of power electronics-based synchronous generator for the integration of renewable energies into the power grid. Int. J. Electr. Power Energy Syst. 2019, 111, 300-314. [CrossRef]

36. Mehrasa, M.; Pouresmaeil, E.; Sepehr, A.; Pournazarian, B.; Marzband, M.; Catalão, J.P.S. Control technique for the operation of grid-tied converters with high penetration of renewable energy resources. Electr. Power Syst. Res. 2019, 166, 18-28. [CrossRef] 